\title{
Thiamin auxotrophy in yeast through altered cofactor dependence of the enzyme acetohydroxyacid synthase
}

\author{
Kerry L. Byrne and Peter A. Meacock \\ Author for correspondence: Peter A. Meacock. Tel: +44 116252 2261. Fax: +44 1162525101. \\ e-mail:mea@le.ac.uk
}

Department of Genetics, University of Leicester, University Road, Leicester LE1 7RH, UK

\begin{abstract}
The THI1 gene of Saccharomyces cerevisiae has been identified and found to be allelic with the previously characterized gene ILV2 that encodes acetohydroxyacid synthase (AHAS). This enzyme catalyses the first step in the parallel biosyntheses of the branched-chain amino acids isoleucine and valine, using thiamin pyrophosphate (TPP) as a cofactor. The ilv2-thi1 allele encodes a functional AHAS enzyme with an altered dependence for the cofactor TPP resulting in the thiamin auxotrophic phenotype. Nucleotide sequence analysis and site-directed mutagenesis revealed that the thi1 mutation is a single base substitution which causes the conserved amino acid substitution D176E in the AHAS protein. This study therefore implicates aspartate 176 as another amino acid residue important either for the efficient binding of TPP by AHAS or for the functional stability of the holoenzyme.
\end{abstract}

Keywords: acetolactate synthase, thiamin pyrophosphate, THI1, ILV2, S. cerevisiae

\section{INTRODUCTION}

Thiamin pyrophosphate (TPP), the biologically active form of vitamin $B_{1}$, is an essential metabolite that serves as cofactor for several key enzymes of intermediary metabolism. These include pyruvate decarboxylase (PDC) [EC 4.1.1.1], pyruvate dehydrogenase E1 subunit (PDH-E1) [EC1.2.4.1; E1], transketolase (TK) [EC 2.2.1.1] and acetohydroxyacid synthase (AHAS) [EC 4.1.3.18]. In recent years AHAS, which catalyses the first step of branched-chain amino acid biosynthesis, has become the subject of detailed research since it is the target of a number of commercial herbicides including the sulfonylureas and imidazolinones (reviewed by Duggleby \& Pang, 2000). Alignment of the amino acid sequences of various TPP-dependent enzymes including PDC, PDH-E1, TK, AHAS, pyruvate oxidase (POX) [EC 1.2.3.3] and 2-oxoglutarate dehydrogenase [EC 1.2.4.2] from yeast, Escherichia coli, humans and plants has revealed a common conserved sequence, GDGX $_{(24-27)}$ NN now termed the 'TPP-binding motif' (Hawkins et al., 1989). These residues are primarily concerned with binding the pyrophosphate end of the

Abbreviations: AHAS, acetohydroxyacid synthase; ALS, acetolactate synthase; PDC, pyruvate decarboxylase; POX, pyruvate oxidase; TK, transketolase; TPP, thiamin pyrophosphate.
TPP molecule through interactions with a divalent cation, generally magnesium.

Thiamin is synthesized in micro-organisms and plants from two precursors, hydroxyethyl thiazole phosphate (HET-P) and hydroxymethyl pyrimidine pyrophosphate (HMP-PP), that are condensed together to form thiamin monophosphate (TMP). In the bakers' yeast Saccharomyces cerevisiae TMP is then dephosphorylated to free thiamin, which is subsequently pyrophosphorylated to form TPP, the endproduct of the pathway. Although some of the enzymes and genes involved in thiamin biosynthesis have been characterized in yeast (reviewed by Begley, 1996; Estramareix \& David, 1996; Hohmann \& Meacock, 1998), much is still unknown. Therefore, in order to learn more about thiamin biosynthesis and metabolism in S. cerevisiae we have embarked upon a genetic analysis of strains carrying thiamin auxotrophic mutations. These included strain Y02587, which carries the first thiamin auxotrophic mutation isolated in $S$. cerevisiae, thi1 (Mortimer \& Hawthorne, 1966). Apart from its nutritional requirements and localization of the thi1 mutation to the right arm of chromosome XIII, no other information was available regarding this strain.

In this paper we describe the isolation of the wild-type THI1 gene. Surprisingly, we found that THI1 is allelic with ILV2, which encodes AHAS. Here we show that thiamin auxotrophy can arise from an alteration in 
cofactor dependence of a TPP-utilizing enzyme rather than through mutation of a structural or regulatory gene of the biosynthetic pathway. We also report that an amino acid residue that does not form part of the consensus TPP-binding motif has a role in determining the cofactor dependency of the enzyme AHAS.

\section{METHODS}

Microbial strains and plasmids. Strains of $S$. cerevisiae used in this study are listed in Table 1 . Since the thi1 mutant strain Y02587 was already uracil requiring (ura1) it was first converted to uracil prototrophy by crossing with a $\mathrm{Ura}^{+}$ derivative of strain W303B, and a thi1 URA1 derivative was isolated from the meiotic progeny. This strain, $\mathrm{Y}_{02587 \mathrm{U}^{+} \text {, was }}$ then crossed against a ura3 strain, PMY3, and KBY6 was isolated from the meiotic products of this cross. Strain W3034ilv2 was made by transforming W303A with a linear ilv24: :URA3 DNA fragment from plasmid pKB22 (see below) and selecting uracil protrophs. Strain KBY8 was created by transforming W303山ilv2 with the linear fragment of insert DNA from plasmid pKB19h (Fig. 1), which carried the allele of the ILV2 gene (ilv2 $\triangle \mathrm{X} b a \mathrm{I}-\mathrm{X} b a \mathrm{I})$ with a deletion of the $1.352 \mathrm{~kb}$ $X b a \mathrm{I}-X b a \mathrm{I}$ section. Cells were plated on medium containing 5-fluoro-orotic acid to select for ura3 derivatives. Transformants were screened for uracil auxotrophy to identify those that had the ilv2 $4:: U R A 3$ allele replaced by the

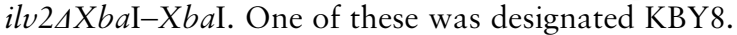

Escherichia coli strains employed as hosts for constructing and propagating plasmids were NM522 (Gough \& Murray, 1983) or the dam strain JM110 (Yanisch-Perron et al., 1985). Luria broth was used for the culture of E. coli and supplemented with ampicillin for the selection of the transformants (Sambrook et al., 1989).

Plasmids used or constructed in this study are listed in Table 1. To construct the ilv24::URA3 deletion allele, DNA of plasmid pKB19c carrying the minimal thi1-complementing fragment was digested with the restriction endonuclease $\mathrm{XbaI}$ and religated to itself, thereby deleting $1.352 \mathrm{~kb}$ of the gene and creating the plasmid pKB19h (Fig. 1). A DNA fragment carrying the URA3 gene was released from pKB22a by $\mathrm{XbaI}$ digestion and ligated into $X b a I$-cut $\mathrm{pKB} 19 \mathrm{~h}$ to give plasmid pKB22, carrying the ilv2::URA3 construct. This plasmid was then digested with HindIII and EcoRI, to recover the $2.29 \mathrm{~kb}$ disruption cassette for transformation into yeast.

Yeast procedures. All standard media and genetic procedures were as described by Sherman (1991). For selective growth, yeast was cultured in SD medium supplemented with the required amino acids and bases. Sporulation was carried out by growth on acetate-based medium, following transfer from rich pre-sporulation medium. To test for thiamin auxotrophy, strains were grown in Wickerham's minimal medium (Wickerham, 1951), with or without thiamin, and supplemented with appropriate amino acids and bases. Highefficiency transformations of yeast were performed by the lithium acetate procedure as described by Geitz et al. (1995). For disruption of the ILV2 locus the 'one-step gene disruption' method was used (Rothstein, 1983). 'Gap repair' was used as described by Orr-Weaver \& Szostak (1983) to recover the ilv2thi1 allele.

Table 1. S. cerevisiae strains and plasmids used in this study

\begin{tabular}{|c|c|c|}
\hline $\begin{array}{l}\text { Strain or } \\
\text { plasmid }\end{array}$ & Relevant genotype or description & Source or reference \\
\hline \multicolumn{3}{|l|}{ Yeasts } \\
\hline DG622 & 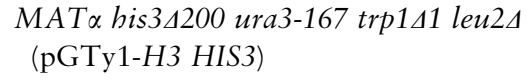 & $\begin{array}{l}\text { J. Strathern, Frederick Cancer } \\
\text { Research Center, MD, USA }\end{array}$ \\
\hline PMY3 & MAT $\alpha$ ura3-52 & Praekelt et al. (1994) \\
\hline PMY3thi4 & MAT $\alpha$ ura3-52 thi4::URA3 & Praekelt et al. (1994) \\
\hline STX573-3C & MATa ilv2 ura3 leu2 gal1 & YGSC \\
\hline W303A & $\begin{array}{l}\text { MATa ade2-1 leu2-3-112 trp1-1 ura3-1 } \\
\text { his 3-11-115 }\end{array}$ & $\begin{array}{l}\text { R. Rothstein, Columbia } \\
\text { University, New York, USA }\end{array}$ \\
\hline W303B & $\begin{array}{l}\text { MAT } \alpha \text { ade2-1 leu2-3-112 trp1-1 ura3-1 } \\
\text { his3-11-115 }\end{array}$ & R. Rothstein \\
\hline Y02587 & MATa thi1 ura1 trp1 & YGSC \\
\hline $\mathrm{Y}_{02587 \mathrm{U}^{+}}$ & MATa thi1 trp1 & This study, Y02587 × W303B \\
\hline W303山ilv2 & W303A ilv2A::URA3 & This study, gene disruption \\
\hline KBY6 & MAT $\alpha$ thi1 ura3-52 trp1 & 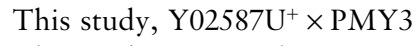 \\
\hline KBY8 & W303A, ilv2s(0.691 kb XbaI-XbaI) & This study, gene replacement \\
\hline \multicolumn{3}{|l|}{ Plasmids } \\
\hline pE16/8-C4 & YRp17-ILV2 & Polaina (1984) \\
\hline pKB19 & Ycp50-THI1 library clone & This study \\
\hline pKB19(c-h) & YCp50-(ilv2 $2 \Delta$ derivatives) (Fig. 1) & This study \\
\hline pKB22a & pUC19-URA3 (XbaI fragment) & This study \\
\hline pKB22 & YCp50-(ilv2A::URA3) & This study \\
\hline pKB24 & YCp50-(ilv2-thi1) & This study \\
\hline pKB29 & pUC19-(ilv2-thi1:sdm) & This study \\
\hline pKB30 & YCp50-(ilv2-thi1:sdm) & This study \\
\hline
\end{tabular}



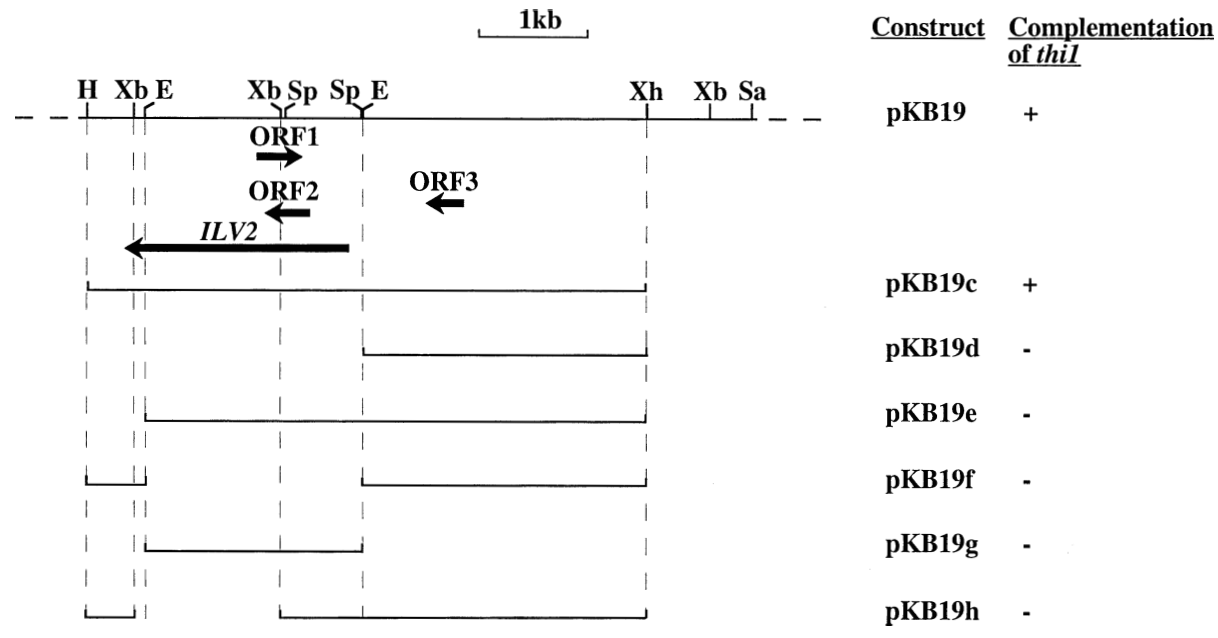

Fig. 1. Localization of the THI1 gene within library clone pKB19: restriction map of a section of the yeast chromosomal DNA contained in this clone. Restriction enzyme sites are E, EcoRI; H, Hindlll; Sa, Sall; Sp, Spel; Xb, Xbal; Xh, Xhol. ORFs are represented by the arrows. ORF3 is YMR107w. Horizontal lines indicate the segments of DNA contained within each of the subclones pKB19c-h. The ability of the various clones to complement the thi1 strain KBY6 to thiamin prototrophy is shown. Transformants were tested on Wickerham's medium either containing or lacking $2 \mu \mathrm{M}$ thiamin; + indicates growth, - indicates no growth.

Table 2. Synthetic oligonucleotides used in this study

\begin{tabular}{|c|c|c|}
\hline Name & Sequence $\left(5^{\prime}-3^{\prime}\right)$ & Target site \\
\hline 1223 & CACTATCGACTACGCGATCA & pBR32 BamHHI clockwise \\
\hline KB9* & CCСGGATCСССТTTGAGCTAAGAGGAG & ILV2 ORF $(-43$ to -27$)$ \\
\hline KB10* & CCCGGATCCGAGAAAGAAGTCGTGTCC & ILV2 ORF (2356 to 2338) \\
\hline KB11 & GCCTGTACGCTTATGACG & ILV2 ORF (2051 to 2033) \\
\hline KB12 & GCTTGAACGGCAGAACTC & ILV2 ORF (1697 to 1679 ) \\
\hline KB13 & CAGACСТСТССТТААСТGG & ILV2 ORF (1336 to 1318) \\
\hline KB14 & CTTGGACCATCTGCATGG & ILV2 ORF (953 to 935) \\
\hline KB15 & GGTTGCCAACGACACAGG & ILV2 ORF (1446 to 1463 ) \\
\hline KB16 & CAGAAGGCTACGCCAGAG & ILV2 ORF (437 to 454 ) \\
\hline KB17 & CCAGTCGCACACAAGATG & ILV2 ORF ( 830 to 847 ) \\
\hline KB18 & GCCAATGGTGGCAGGTGG & ILV2 ORF (1956 to 1973 ) \\
\hline KB19† & TCCAATGGCAGAGGCCTTTGCAGAC & ILV2 ORF (516 to 540 ) \\
\hline $\mathrm{KB} 20+$ & GTCTGCAAAGGCĒTCTGCCATTGGA & ILV2 ORF (540 to 516 ) \\
\hline KB21 & GTATTTCTCTTAT̄CTGGTTG & ILV2 ORF $(-289$ to -269$)$ \\
\hline KB22 & GTCAGCCTCTTGGAAAGC & ILV2 ORF (615 to 599) \\
\hline
\end{tabular}

* Bam HI restriction enzyme site (underlined) incorporated at the 5 ' end.

† Mismatched base (underlined) incorporated at centre of the sequence.

DNA manipulations. Standard DNA handling procedures were carried out according to protocols described in Sambrook et al. (1989). Total yeast chromosomal DNA of high quality, for use in Southern blot analysis, was prepared from spheroplasts (Cryer et al., 1975). DNA samples were sequenced on an ABI model 373A DNA sequencer, following sample preparation using the PRISM Ready Reaction DyeDeoxy Terminator Cycle Sequencing Kit. The primer for sequencing DNA cloned into the BamHI site in YCp50 DNA was obtained from New England Biolabs; 1223, pBR322 BamHI site primer (clockwise). Custom-made primers were supplied by PNACL at Leicester University and are listed in Table 2 .
Site-directed mutagenesis was performed using oligonucleotide primers with mismatched bases. Thus primers KB19 and KB20 (Table 2) were designed complementary to both strands of DNA to cover the $25 \mathrm{bp}$ region surrounding the thi1 mutation, T528G, that was to be introduced. These primers, along with $\mathrm{KB} 21$ and $\mathrm{KB} 14$, which annealed to the flanking ILV2 DNA either side of the mutation site, were used to amplify the two halves of the ILV2 gene by PCR. The products of these two reactions were recovered, mixed together, denatured and used as template for PCR using only the two flanking primers KB21 and KB14. The product obtained was a $1.24 \mathrm{~kb}$ fragment of ILV2 sequence with the introduced thi1 mutation. This was purified and digested with 
SpeI, to release a 691 bp fragment, containing the site-directed mutation. This fragment was ligated into SpeI-cut pKB18h to make pKB29, which contained the ilv2-thi1:sdm gene on vector pUC19. This clone was digested with the restriction endonuclease StuI, to confirm that the thi1:sdm mutation had been correctly incorporated, and the $691 \mathrm{bp}$ SpeI fragment was sequenced using primers KB14, KB16 and KB21. The DNA construct pKB29, which was confirmed to contain no other mutations, was then digested with restriction endonucleases HindIII and SalI to release the mutant ilv2-thi1 :sdm gene. This was ligated into HindIII-SalI-digested YCp50 DNA to create the plasmid pKB30 used for introduction of the sitedirected mutant allele into yeast.

Acetohydroxyacid synthase (AHAS) assay. Yeast strains were grown overnight $(25$ or $50 \mathrm{ml})$ to a concentration of $1-3 \times 10^{7}$ cells $\mathrm{ml}^{-1}$, in Wickerham's minimal medium supplemented with tryptophan, histidine, adenine, isoleucine and valine. Cells were harvested at 5000 r.p.m. for $5 \mathrm{~min}$, washed twice in sterile distilled $\mathrm{H}_{2} \mathrm{O}$ and resuspended in $1.0 \mathrm{ml} 0.1 \mathrm{mM}$ Tris/HCl buffer (pH 7.5), $0 \cdot 1 \mathrm{M} \mathrm{NaCl}, 0 \cdot 1 \mathrm{mM}$ EDTA at $4{ }^{\circ} \mathrm{C}$ containing the protease inhibitors chymostatin $\left(1 \mu \mathrm{g} \mathrm{ml}^{-1}\right)$, PMSF $(1 \mathrm{mM})$ and pepstatin $(1 \mu \mathrm{M})$. These were permeabilized by adding $100 \mu \mathrm{l}$ chloroform and vortexing for $30 \mathrm{~s}$, collected by centrifugation and the supernatant was decanted. After resuspension in $1.0 \mathrm{ml}$ of the same buffer the total protein concentration was measured using the Bio-Rad 'Bradford Reagent' method. AHAS was assayed via its acetolactate synthase (ALS) activity. Acetolactate production was measured at $30^{\circ} \mathrm{C}$ for $30 \mathrm{~min}$, using a method based on that of Ryan \& Kohlhaw (1974). For each assay two tubes were set up, $A$ and $B$, each containing a mixture of $40 \mathrm{mM}$ sodium pyruvate, $10 \mathrm{mM} \mathrm{MgCl}_{2}, 100 \mathrm{mM}$ Tris/ $\mathrm{HCl}(\mathrm{pH} 7 \cdot 5$ ) and varying concentrations of TPP $(0-200 \mu \mathrm{M})$, to a total volume of $100 \mu \mathrm{l}$. The reactions were started by the addition of $\sim 0.5 \mathrm{mg}$ permeabilized cell protein to each tube. They were stopped by the addition of $50 \mu 13 \mathrm{M}$ sulphuric acid to tube A and $150 \mu \mathrm{l} 6 \mathrm{M}$ sodium hydroxide to tube B. The yield of acetolactate produced was determined by converting it to acetoin. This involved measuring the total amount of acetoin produced (tube A) and subtracting the amount of background acetoin produced by the cells (tube B). Acetolactate was converted into acetoin by a decarboxylation step that involved heating the sample in an acid environment. Therefore tube A was incubated at $60^{\circ} \mathrm{C}$ for $30 \mathrm{~min}$, after which the sample was made basic by the addition of $100 \mu 12 \mathrm{M}$ sodium hydroxide. Acetoin was measured according to the method of Westerfeld (1945). Each sample was made up to a total volume of $1 \mathrm{ml}$ with sterile distilled water, then $200 \mu \mathrm{l} 0.5 \%$ creatine was added followed by $200 \mu \mathrm{l} 5 \% \alpha$-naphthol (freshly made up in $2 \cdot 5 \mathrm{M}$ sodium hydroxide) and the solution mixed by inverting the tubes several times. The colour was allowed to develop for $1 \mathrm{~h}$ at room temperature, the samples were centrifuged for $2 \mathrm{~min}$ and then their absorbance at $540 \mathrm{~nm}$ was measured against a blank made up of $1 \mathrm{ml}$ water, $200 \mu \mathrm{l}$ creatine and $200 \mu \mathrm{l} \alpha$-naphthol. The ALS activity was calculated as acetoin produced per mg of permeabilized cell protein per minute.

\section{RESULTS}

\section{Molecular cloning of the wild-type THI1 gene}

The first documented thiamin-auxotrophic strain of $S$. cerevisiae, Y02587, isolated in the 1960s, carries a mutation designated thil (Mortimer \& Hawthorne, 1966). We obtained Y02587 from the Yeast Genetic Stock Center (YGSC), University of California,
Berkeley, USA, and carried out genetic analysis. When the thil mutant strain was crossed with a $\mathrm{Ura3}^{+}$ derivative of the thiamin-prototrophic strain W303B, the heterozygous diploid was found to be prototrophic for thiamin. Therefore the thi1 mutation is recessive. The diploid strain was induced to undergo sporulation and 12 four-spore meiotic tetrads were dissected. All tetrads showed 2:2 segregation of the $\mathrm{Thi}^{-}$and $\mathrm{Thi}^{+}$ phenotypes, confirming that thi1 is a single-locus mutation.

In order to test whether the thi1 mutation was allelic with other known mutants which gave thiamin auxotrophy, thi2 (Kawasaki et al., 1990), thi3 (Nishimura et al., 1992), thi4 (Praekelt et al., 1994) and thi6 (Nosaka et al., 1994), complementation analysis was performed. Appropriate crosses were made between the thi1 mutant and each of the other mutant strains, and the heterozygous diploids were tested for thiamin requirement; all of the diploids were prototrophic for thiamin. Thus thi1 is not allelic with the thiamin mutations thi2, thi3, thit or thi6.

DNA clones that complemented the thi1 mutation were obtained on the basis of their ability to rescue growth of the mutant on thiamin-deficient medium. A thi1 ura3 strain (KBY6) was transformed to uracil prototrophy using a YCp50-based S. cerevisiae genomic DNA library (Rose et al., 1987). Among the several thousand $\mathrm{Ura}^{+}$ transformants recovered, 19 were thiamin prototrophs; in all cases $\mathrm{Ura}^{-}$segregants that had lost the transforming clones displayed thiamin auxotrophy, indicating that the prototrophic phenotype of the transformants was caused by the introduced library plasmid and not by reversion of the original thi1 mutation. Plasmid DNAs were recovered into E. coli from two of the transformants and these were found to complement the thi1 mutation when retransformed back into the KBY6 strain, confirming that each carried the THI1 gene.

Restriction enzyme digestions revealed that the yeast genomic DNA fragments in the two plasmids were identical. Subcloning of the insert DNA from one plasmid (pKB19) gave a $5 \cdot 185 \mathrm{~kb}$ HindIII-XhoI fragment that was able to complement the thi1 mutation when reintroduced into KBY6 on vector YCp50 (pKB19c, Fig. 1). Nucleotide sequence data were obtained from the ends of the insert DNA and compared with the EMBL nucleotide database. The sequence of the insert DNA was found to match the region of yeast chromosome XIII containing the ORF YMR108w, previously characterized as the ILV2 gene. Analysis of the sequence of the $5.185 \mathrm{~kb}$ DNA fragment revealed three other potential ORFs, all smaller than $420 \mathrm{bp}$ in length (Fig. 1). Further dissection of the DNA fragment carried in pKB19c produced the smaller derivatives pKB19d-h (Fig. 1); phenotypic analysis showed that none of these was able to rescue the thiamin auxotrophy of thi1. These subclones included pKB19g, carrying only the internal $2.0 \mathrm{~kb}$ EcoRI fragment, and the reciprocal derivative, pKB19f, that had this fragment deleted. 


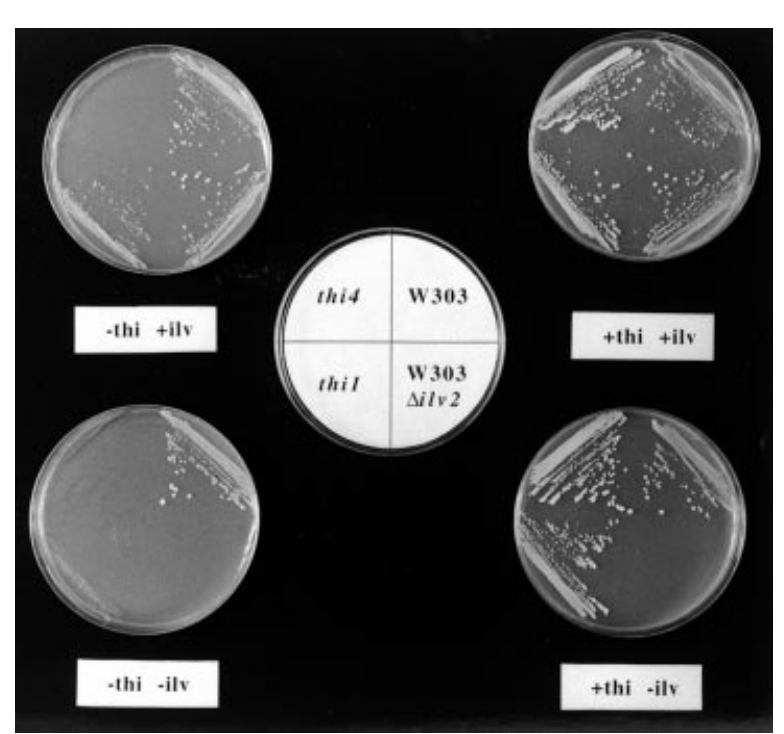

Fig. 2. Phenotype of the thi1 mutant strain: thiamin and isoleucine/valine growth tests of mutant yeast strains. Single colonies were diluted in sterile water and standard aliquots streaked onto Wickerham's minimal medium plus required amino acids and bases, supplemented with nothing (-thi -ilv), or with thiamin (+thi -ilv), or with isoleucine/valine (-thi $+\mathrm{ilv})$, or with both (+thi $+\mathrm{ilv})$. Strains used were as follows: $\mathrm{W} 303=\mathrm{W} 303 \mathrm{~B}\left(\mathrm{Thi}^{+} \mathrm{Ilv}^{+}\right.$control); thi4 = PMY3thi4::URA3 $\left(\mathrm{Thi}^{-}\right.$ control); W303Ailv2 = W303A,ilv2 $4:$ URA3 (Ilv ${ }^{-}$control); thi1 = Y02587.

These data suggested that the ORF responsible for thi1 complementation spanned one or both of these EcoRI sites and thus ruled out ORFs 1 and 2 as candidates for the THI1 gene, as both were contained entirely within the $2 \cdot 0 \mathrm{~kb}$ fragment. Also ORF 3 (YMR107w) was eliminated because it was located entirely outside this region. Therefore the only ORF which spanned one or both of the EcoRI sites was YMR108w, the ILV2 gene.

\section{Allelism of thi1 and ILV2}

Normally mutations at the ILV2 locus cause auxotrophy for the branched-chain amino acids isoleucine and valine (Falco \& Dumas, 1985). However, the thi1 strain Y02587 did not require isoleucine and valine for growth (Fig. 2). Furthermore, a strain (STX573-3C) previously confirmed to carry a bona fide ilv2 mutation showed isoleucine and valine auxotrophy but no requirement

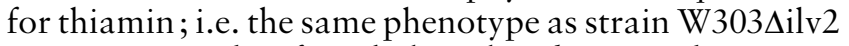
(Fig. 2). We also found that the thi1-complementing clone, pKB19c, conferred isoleucine and valine prototrophy when transformed into strain STX573-3C, indicating that it carried an ILV2 allele. Likewise a bona fide ILV2 clone, pE16/8-C4 (Polaina, 1984), was able to restore thiamin prototrophy when transformed into the thi1 strain KBY6. This gave an intriguing paradox: the thi1 mutant was not isoleucine and valine requiring and the ilv2 mutant was not thiamin requiring, yet both mutations were complemented to their respective prototrophies by the same fragment of DNA. One explanation
Table 3. Meiotic segregation of thiamin and isoleucine/valine phenotypes in the cross W303 $\Delta$ ilv2 (Ailv2::URA3) $\times$ KBY6 (thi1)

\begin{tabular}{|lrccc|}
\hline $\begin{array}{l}\text { Minimal medium } \\
\text { supplements }\end{array}$ & \multicolumn{4}{c|}{$\begin{array}{c}\text { No. of tetrads of segregation pattern } \\
\text { (growth: no growth) }\end{array}$} \\
\cline { 2 - 5 } & $\mathbf{2 : 2}$ & $\mathbf{3 : 1}$ & $\mathbf{4 : 0}$ & $\mathbf{0 : 4}$ \\
\hline + Thi + Ilv & 0 & 0 & 10 & 0 \\
- Thi + Ilv & 0 & 0 & 10 & 0 \\
+ Thi - Ilv & 10 & 0 & 0 & 0 \\
- Thi - Ilv & 0 & 0 & 0 & 10 \\
\hline
\end{tabular}

could be that YMR108w was the wild-type locus for one of the mutations and a suppressor of the other. However the complementing fragments were carried on lowcopy-number vectors, which made suppression unlikely. It was therefore important to delete this locus and examine the phenotype of the resultant ilv2 $2 \Delta$ null mutant. Additionally, examination of the meiotic segregants of diploids made by crossing strains carrying the ilv 24 and thi1 mutations would help to resolve whether they were allelic.

To this end 'one step' gene replacement (Rothstein, 1983) was carried out at the ILV2 locus. A linear DNA fragment, comprising the genomic DNA insert of plasmid pKB19c (Fig. 1) with the $1.35 \mathrm{~kb} \mathrm{XbaI} \mathrm{fragment}$ from within the ILV2 gene replaced with a URA3 gene, was recovered from plasmid $\mathrm{pKB} 22$, transformed into the yeast strain W303a, and uracil prototrophs selected. This DNA fragment underwent targeted recombination with the ILV2 locus because of the homologous sequences flanking the selected URA3 marker gene. Replacement of the ILV2 gene by the introduced ilv2 $2:: U R A 3$ construct in one of the $\mathrm{Ura}^{+}$trans-

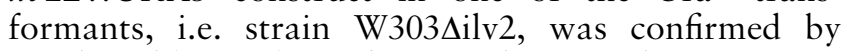
Southern blot analysis (data not shown). This strain was also found to display isoleucine and valine auxotrophy but thiamin prototrophy, i.e. it was phenotypically $\mathrm{Ilv}^{-}$ $\mathrm{Thi}^{+}$(Fig. 2).

Because of this observation we decided to reinvestigate the phenotype of strains carrying the original thi1 mutation. We found that the haploid thi1 strain did not in fact require thiamin for growth when isoleucine and valine were supplied in the medium (Fig. 2). Therefore the true phenotype of the thi1 mutation is that of thiamin auxotrophy only in the absence of isoleucine and valine.

Finally, we crossed the strain W303Ailv2 carrying the ilv24::URA3 allele and the thi1 strain KBY6. The heterozygous diploid exhibited the thi1 phenotype (thiamin auxotrophy in the absence of isoleucine and valine). Sporulation and analysis of 10 meiotic tetrads was carried out (Table 3). In the presence of isoleucine and valine 4:0 segregation of $\mathrm{Thi}^{+}: \mathrm{Thi}^{-}$phenotypes was observed for all tetrads. However, in the absence of 
isoleucine and valine only two spores from each tetrad were viable with thiamin supplementation, and no spores were viable in the absence of thiamin as well as isoleucine and valine. Taken together these observations implied that the ilv2A and thi1 mutations showed 2:2 segregation consistent with their being allelic. Moreover the absence of any non-parental ditype or tetratype tetrads confirmed that the thi1 and ilv $2 \Delta$ mutations were tightly linked.

\section{Characterization of the thi1 mutation}

These paradoxical observations led to the conclusion that the thi1 mutation defines a unique allele of the ILV2 gene that has no direct function in the biosynthesis of thiamin. We propose that it be redefined as the ilv2-thi1 allele. Since AHAS requires TPP as a coenzyme it seemed likely that the ilv2-thi1 allele encodes a functional AHAS enzyme with an enhanced requirement for thiamin. Such a situation could arise if the AHAS produced had a reduced binding affinity for TPP. By adding exogenous thiamin to the medium the internal concentration of TPP is raised, due to active thiamin uptake and conversion to TPP, which is then stored within the cell (Iwashima et al., 1973; Suzuoki, 1955; Praekelt et al., 1994). Thus, we reasoned that the variant AHAS produced from the ilv2-thi1 allele only functions effectively in branched-chain amino acid biosynthesis when intracellular TPP levels are high. In contrast, the normal AHAS enzyme, produced from the wild-type ILV2 allele, has sufficient affinity for TPP that it can function using the normal low endogenous level of cofactor. Supplementation with exogenous isoleucine and valine would completely obviate the need for AHAS function and therefore would allow ilv2-thi1 mutants to grow without additional thiamin.

To test this hypothesis we decided to investigate the molecular nature of the thi1 mutation and to characterize the AHAS enzyme produced from the ilv2-thi1 allele. Recovery of the mutant allele was achieved using the 'gap repair' technique (Orr-Weaver \& Szostak, 1983). Cells of the thi1 ura3 strain KBY6 were transformed to uracil prototrophy with $\mathrm{XbaI}$-linearized DNA of the ARS-CEN-based plasmid pKB19h (Fig. 1) which had part of the ILV2 sequence deleted from the insert DNA. The in vitro-generated gap in the transforming DNA was repaired by in vivo recombination with the homologous chromosomal sequences. Plasmid DNAs from two different $\mathrm{Ura}^{+}$transformants were recovered into E. coli and then transformed back into the ura3 ilv2 2 strain KBY8. Transformants carrying each plasmid clone gave the thi1 phenotype, thiamin auxotrophy in the absence of isoleucine and valine, confirming that we had recovered the ilv2-thi1 allele.

In order to establish exactly where the thil mutation was located and to determine its effect on the AHAS amino acid sequence, we carried out nucleotide sequencing of the mutant ORF of one plasmid, pKB24, using oligonucleotide primers (Table 2). Only a single nucleotide difference was found within the $2064 \mathrm{bp}$ (a)

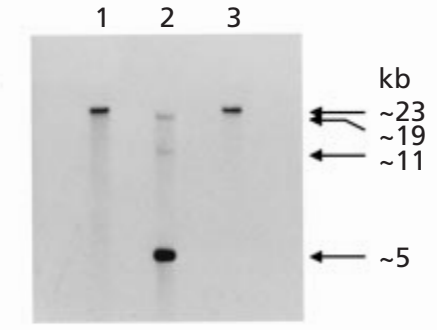

(b)

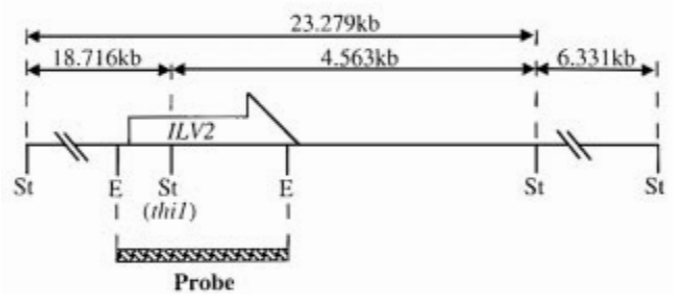

Fig. 3. (a) Confirmation of the thi1 mutation: autoradiograph from Southern blot analysis of genomic DNA $(3 \mu \mathrm{g})$ digested with restriction endonuclease Stul and hybridized with a probe made from the $2.0 \mathrm{~kb}$ EcoRI fragment of ILV2 DNA in plasmid pKB19c. DNAs were isolated from strains W303B (THI1) (lane 1), KBY6 (thi1) (lane 2), and DG622 (THI1) (lane 3). The $11 \mathrm{~kb}$ band that appears in lane 2 is the product of incomplete digestion at an adjacent Stul site, and comprises the $4.563 \mathrm{~kb}$ fragment with the adjoining $6.331 \mathrm{~kb}$ fragment (see b). (b) Restriction map of the ILV2 region, showing the location of the additional Stul site introduced into the ILV2 gene by the thi1 mutation, and sizes of hybridizing fragments. Restriction enzyme sites are $\mathrm{E}$, EcoRI; St, Stul.

sequence of the ilv2-thi1 allele when compared to the published ILV2 sequence (Falco et al., 1985). The mutation at nucleotide position 528 of the ILV2 ORF (YMR108w) was a T to $\mathrm{G}$ transversion changing codon 176 from GAT to GAG, and thereby replacing the normal aspartate residue with the related glutamate, i.e. D176E. Moreover, the mutation also created a new cleavage site for the restriction endonuclease StuI : $5^{\prime}$ ATGCCT-3' to $5^{\prime}$-AGGCCT-3'. However the thi1 mutation was located $100 \mathrm{bp}$ upstream from the $5^{\prime} \mathrm{XbaI}$ site used for the 'gap repair' cloning of the ilv2-thi1 allele. Thus recombination between the transforming gapped plasmid and ilv2-thi1 sequences must have extended well beyond the ends of the linearized plasmid DNA.

To confirm that strains carrying the original ilv2-thi1 allele did contain this particular mutation within the ILV2 ORF we carried out a Southern blot analysis to look for the presence of the additional StuI site. Genomic DNAs were isolated from the thi1 strain KBY6 and two $\mathrm{Thi}^{+} \mathrm{Ilv}^{+}$strains, DG622 and W303B; these were digested with restriction enzyme $S t u \mathrm{I}$ and subjected to Southern blot analysis using part of the ILV2 gene as a hybridization probe (Fig. 3). Inspection of the published sequence of chromosome XIII (Bowman et al., 1997) 


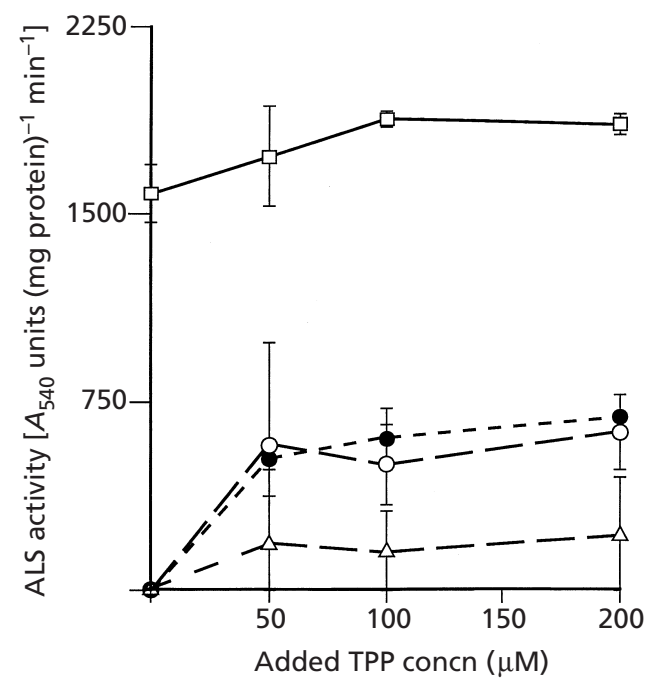

Fig. 4. Acetolactate synthase assays. ALS activity was measured in permeabilized cells of strain KBY8 containing various alleles of the ILV2 gene on the vector YCP50. Increasing concentrations of TPP were added to the assay mix. Activity was calculated as acetoin produced $\left[A_{540} \text { units (mg total protein }\right)^{-1}$ $\mathrm{min}^{-1}$ ]. Duplicate samples were taken, and each measurement is the mean of two independent experiments; error bars indicate standard errors. Symbols indicate the following plasmids: $\square$, pKB19c (ILV2); O, pKB24 (ilv2-thi1); O, pKB30 (ilv2-thi1:sdm); $\triangle$, YCp50 (ilv24).

showed that ILV2 is contained within a $23 \cdot 279 \mathrm{~kb}$ StuI fragment. The DNAs of strains W303B and DG622 both yielded a single hybridizing fragment of approximately $23 \mathrm{~kb}$ (Fig. 3, lanes 1 and 3). However, DNA of strain KBY6 yielded two smaller hybridizing fragments, of approximately $5 \mathrm{~kb}$ and $19 \mathrm{~kb}$ (Fig. 3, lane 2). These corresponded to the sizes of fragments $(4.563 \mathrm{~kb}$ and $18.716 \mathrm{~kb}$ ) that would be produced if an extra StuI restriction site had been created at nucleotide 528 of the ILV2 ORF. Therefore the mutation generating the StuI restriction site was present in strains carrying the original thi1 allele.

As final proof that this single base change was solely responsible for conferring the thil phenotype we performed a PCR-based site-directed mutagenesis experiment. Using mismatched oligonucleotide primers (KB19, KB20; Table 2) the $\mathrm{T}_{528} \mathrm{G}$ substitution was introduced into the ILV2 gene carried on plasmid pUC19 to make pKB29 (Table 1). After confirmation of the mutation by nucleotide sequencing, the mutated gene (ilv2-thi1:sdm) was transferred to the vector YCp50 to create pKB30, which was transformed into the KBY8 strain. All of the $\mathrm{Ura}^{+}$transformants exhibited the thi1 phenotype, confirming that the single base change was indeed solely responsible for the thi1 phenotype.

\section{AHAS activity in thi1 mutants}

We have postulated that the thi1 mutant might produce a variant of AHAS that has altered dependence for its cofactor TPP, so that the enzyme can only function in branched-chain amino acid biosynthesis when intracellular TPP levels are raised by exogenous supply of thiamin. To test this hypothesis we assayed AHAS activity, and its TPP dependency, in yeast strains carrying various alleles of $I L V 2$. Acetolactate synthase (ALS) activity, one of the two activities of AHAS, was measured in the KBY8 strain carrying different ILV2 alleles on low-copy-number plasmids: pKB19c (ILV2), pKB24 (ilv2-thi1), pKB30 (ilv2-thi1:sdm) and YCp50 (ilv24).

Permeabilized cells carrying the wild-type ILV2 allele (pKB19c) were found to have high levels of activity that showed little dependence on TPP concentration over the range 50-200 $\mu \mathrm{M}$ (Fig. 4). Even with no additional TPP high levels of acetolactate were produced, indicating that the cells contained sufficient endogenous TPP for almost full ALS activity. In contrast, permeabilized cells carrying the ilv2-thi1 allele (pKB24) showed no or little ALS activity in the absence of exogenous TPP; addition of the cofactor stimulated activity but never to the very high levels recorded in the ILV 2 cells. The data obtained from the enzyme produced by the site-directed mutagenesis clone pKB30, ilv2-thi1:sdm, were virtually identical to those obtained for AHAS produced from the original ilv2-thi1 mutant allele. Again, there was no measurable ALS activity when no exogenous TPP was added to the assay mixture, but activity was detected as the TPP concentration was increased.

We did observe a low background level of TPPdependent acetolactate production in cells containing no copy of the ILV2 gene, i.e. ilv2 24 . This suggests that there may be another enzyme in yeast that can carry out an ALS-type reaction converting pyruvate to $\alpha$-acetolactate at a very low rate.

\section{DISCUSSION}

We have shown that the thil mutation of $S$. cerevisiae defines a novel allele of the ILV2 gene encoding the first enzyme of branched-chain amino acid biosynthesis, AHAS. The phenotype conferred is that of thiamin auxotrophy in the absence of isoleucine and valine (Fig. 2 ). We have proposed that the ilv2-thi1 allele encodes a mutant AHAS enzyme, with altered dependence for its cofactor TPP, that only functions effectively in cells with raised intracellular TPP levels brought about by an exogenous supply of thiamin. Addition of the branchedchain amino acids isoleucine and valine to the culture medium obviates the need for AHAS activity and so also alleviates the thiamin requirement (Fig. 2). Consistent with our hypothesis, enzyme assays showed that, for any given concentration of TPP, yeast cells containing the wild-type ILV2 allele had a higher ALS activity than cells containing the ilv2-thi1 allele (Fig. 4). The actual thi1 mutation is a $T$ to $G$ single base transversion at nucleotide 528 of the ILV2 ORF, which translates to a conservative amino acid substitution of glutamate for aspartate at residue 176 of the protein, D176E. This change is situated in the amino-terminal one-third of the protein and distant from the conserved TPP-binding 


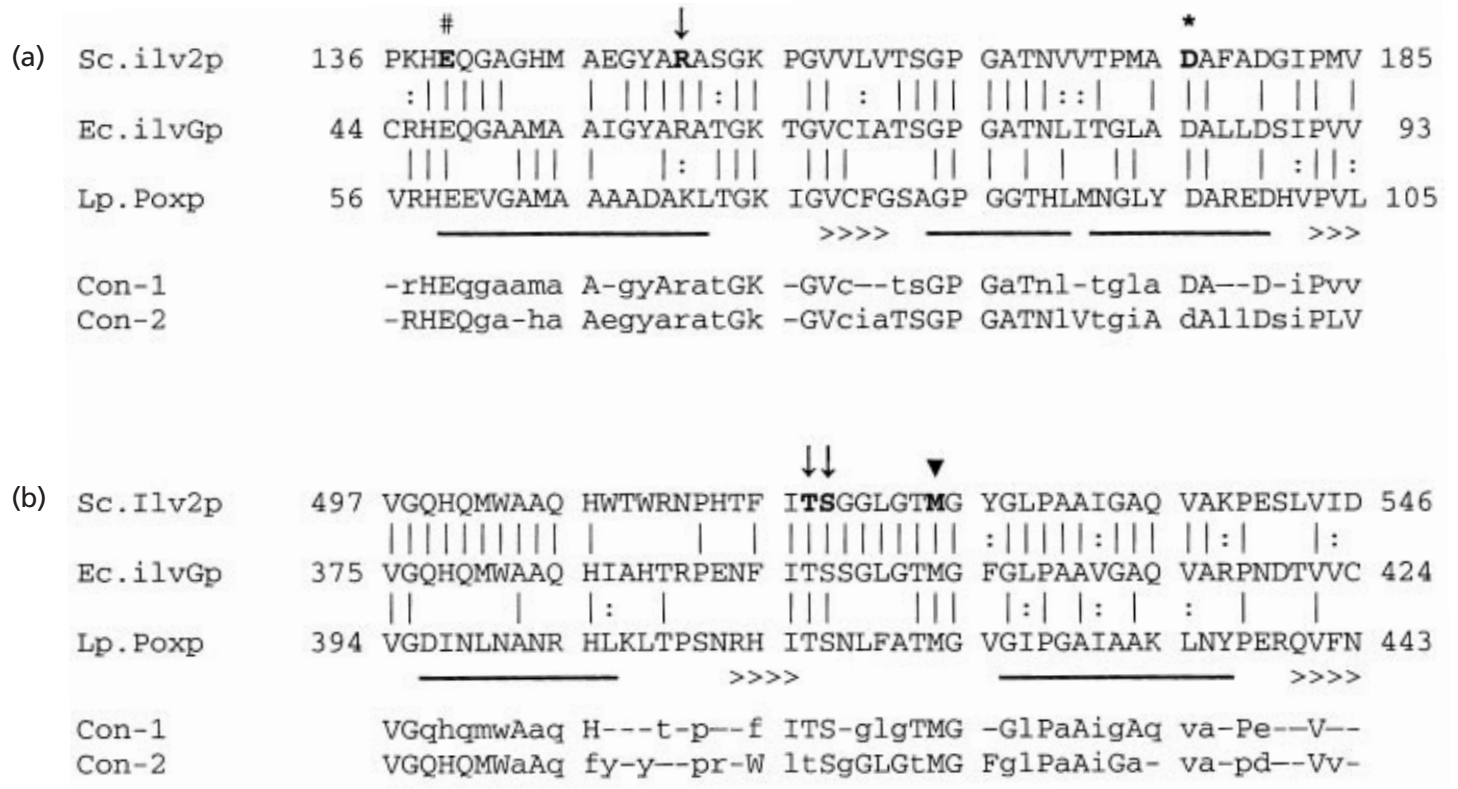

\begin{abstract}
Fig. 5. Alignment of partial amino acid sequences of AHAS and POX proteins. The amino acid sequences of $S$. cerevisiae and $E$. coli AHAS were aligned with that of $L$. plantarum POX, for which the three-dimensional structure has been elucidated. Shown here are two parts of that comparison: (a) the region surrounding the site of the thi1 mutation in Scllv2p; (b) the loop of AHAS containing residues T518 and S519, which may interact structurally with D176 in Scllv2p. Sc.ilv2p, S. cerevisiae AHAS; Ec.ilvGp, E. coli AHAS II; Lp.Poxp, L. plantarum POX. Con-1, consensus sequence from Sc.Ilv2p, Ec.ilvGp and Lp.Poxp; Con-2, consensus sequence from trans-kingdom comparison of 11 AHASs taken from Chipman et al. (1998); in both consensus sequences upper-case denotes the most frequently occurring residue. The symbols \#, * and $\boldsymbol{\nabla}$ denote residues E139, D176 and M525 of Scllv2p respectively, and the vertical arrows $(\downarrow)$ indicate potentially interacting residues, R151, T518 and S519 (see text). Structural elements of Lp.Poxp are shown below the sequence: horizontal arrowheads $(\gg)$ are $\beta$-strands; bold horizontal bars are $\alpha$-helices. The line-up of Ec.ilvGp and Lp.Poxp is taken from Ibdah et al. (1996).
\end{abstract}

consensus sequence, which is located towards the carboxyl terminus (residues 547-577).

The structures of three enzymes that use TPP as a cofactor have been resolved by X-ray crystallography. These are PDC from S. cerevisiae (Dyda et al., 1993), TK from S. cerevisiae (Lindqvist et al., 1992; Nilsson et al., 1993) and POX from Lactobacillus plantarum (Muller \& Schultz, 1993). AHAS has homology to all of these but is most closely related to POX, sharing 29-30\% amino acid identity. Indeed, E. coli AHAS II (EcilvGp) has previously been modelled on the crystal structure of LpPoxp (Ibdah et al., 1996); both enzymes use the same cofactors, substrate and initial catalytic step and E. coli POX has been found to have a low AHAS activity (Chang \& Cronan, 1988). Alignment of the amino acid sequences of AHAS from S. cerevisiae and E. coli (AHAS II) with that of L. plantarum POX (LpPoxp) revealed that the aspartate residue that is altered by the thi1 mutation is conserved between these three sequences; D176 of yeast AHAS aligns with D84 of AHAS II of E. coli and with D96 of L. plantarum POX (Fig. 5). Moreover, in a trans-kingdom comparison of AHAS sequences from eubacteria, archaea and eukaryotes (Chipman et al., 1998) this aspartate was conserved in eight out of the eleven polypeptides, with an identical substitution by threonine in the other three.
The POX enzyme is a homotetramer, arranged as a pair of dimers, with each monomer comprising three domains: core (residues 9-191); FAD-binding domain (residues 192-342); and TPP-binding domain (residues 343-593) (Muller \& Schultz, 1993). The homology modelling of AHAS has indicated that, as in POX, two TPP molecules are bound by each dimer in pockets between the first domain of one subunit and the third domain of the other subunit, in a head-to-tail fashion (Ibdah et al., 1996). The POX D96, and by analogy D176 in yeast AHAS (Fig. 5), is located in the amino-terminal core domain along with the catalytic glutamate residue, E59 in POX and E139 in yeast AHAS (Fig. 5), that is conserved in all TPP-dependent enzymes. The core domains of the four monomers are closely packed at the centre of the holoenzyme and, by implication, hold the subunits together. Therefore the D176E mutation, which introduces an extra methylene group into the amino acid side chain, may affect dimerization and/or oligomerization of the AHAS subunits, and so affect TPP binding.

To try to gain more information about the structural effects of the thi1 mutation we used the RasMol program (Sayle \& Milner-White, 1995), taking the LpPoxp structure as a template, to model the predicted threedimensional structures of the Scilv $2 p$ in the wild-type 

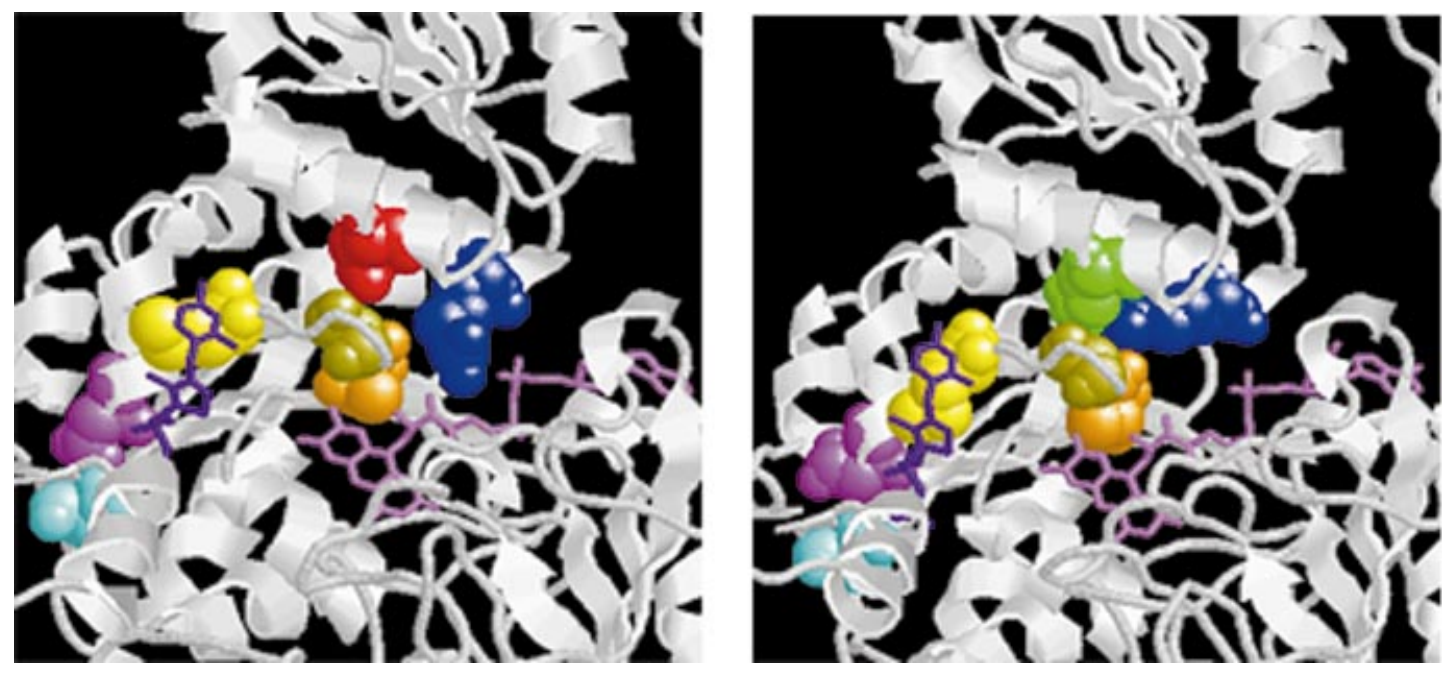

Fig. 6. Structural changes to Scllv2p caused by the thi1 mutation. Left-hand panel, wild-type Ilv2p monomer; right-hand panel, mutant Ilv2p (D176E) monomer. Using the RasMol v2.6 program the three-dimensional structures of monomers of wild-type and mutant Scllv2p were predicted, based on LpPoxp as a model. The view shows the part of the polypeptide affected by the thi1 mutation, and the 'core', 'TPP-binding' and 'FAD-binding' domains are located at the top, centre left and bottom right respectively. The polypeptide backbone is shown as a 'cartoon' diagram; ligands TPP and FAD are shown as purple and violet 'stick' models, respectively. Key amino acid residues (see text) are denoted by coloured 'spacefill' structures: D176, red; E176, green; R151, blue; T518, orange; S519, olive; M525, yellow; D550, magenta; N577, cyan.

(D176) and mutant (D176E) forms (Fig. 6). A loop of the TPP-binding domain, containing residues T518 and S519, was found to lie at the interface with the core domain, between the D176 residue and the two ligands TPP and FAD. This serine residue, S519 of Scilv2p, is conserved in all 11 AHAS sequences of the transkingdom analysis (Chipman et al., 1998) and in LpPoxp (Fig. 5), and lies close to the conserved methionine residue (M525 in Scilv2p) that has been implicated in determining the conformation of the bound TPP (Duggleby \& Pang, 2000); residues of Scilv2p that interact with the phosphate of TPP via a co-ordinated $\mathrm{Mg}^{2+}$ anion are D550 and N577 (Duggleby \& Pang, 2000). In the wild-type configuration residue D176 can form a hydrogen bond across the domain interface with the residue S519. However, the mutant residue E176 does not form this hydrogen bond but instead forms a salt-bridge with R151, also of the core domain. In wildtype AHAS, R151 forms a hydrogen bond with the backbone oxygen of T518 but this interaction probably does not occur in the mutant because of the interference by E176. Thus the thi1 mutation, which substitutes a glutamate for an aspartate residue at position 176 , is likely to break the hydrogen-bonding network across this domain interface of the monomer, ultimately reducing the binding affinity of AHAS enzyme for the TPP ligand.

To the best of our knowledge our study has shown, for the first time in a micro-organism, that thiamin auxotrophy can arise from an alteration in cofactor dependence of a TPP-utilizing enzyme rather than through mutation of a component of the biosynthetic pathway. This is somewhat analogous to the situation in human patients suffering from Wernicke-Korsakoff syndrome, where an assembly defect of the TPP-dependent enzyme transketolase, TK, causes a neurological disorder potentiated by thiamin deficiency (Wang et al., 1997).

\section{ACKNOWLEDGEMENTS}

This work was supported by BBSRC Research Grants GR/J66362 and 91/G08756 to P.A.M. The ILV2 plasmid pE16/8-C4 was a kind gift from Professor M. Keilland-Brandt (Copenhagen). We are grateful to Simon Elliston-Elhinn for helpful discussions about the thi1 mutant phenotype and to Mike Sutcliffe, Department of Chemistry, for guidance on use of the RasMol program and interpretation of the structural data.

\section{REFERENCES}

Begley, T. P. (1996). The biosynthesis and degradation of thiamin (vitamin-B1). Nat Prod Rep 13, 177-185.

Bowman, S., Churcher, C., Badcock, K. \& 18 other authors (1997). The nucleotide sequence of Saccharomyces cerevisiae chromosome XIII. Nature 378 (suppl), 90-93.

Chang, Y. Y. \& Cronan, J. E. (1988). Common ancestry of Escherichia coli pyruvate oxidase and the acetohydroxy acid synthases of the branched-chain amino-acid biosynthetic pathway. J Bacteriol 170, 3937-3945.

Chipman, D., Barak, Z. \& Schloss, J. V. (1998). Biosynthesis of 2aceto-2-hydroxy acids: acetolactate synthases and acetohydroxyacid synthases. Biochim Biophys Acta 1385, 401-419.

Cryer, D. R., Eccleshall, R. \& Marmur, J. (1975). Isolation of yeast DNA. Methods Cell Biol 12, 39-44.

Duggleby, R. C. \& Pang, S. S. (2000). Acetohydroxyacid synthase. J Biochem Mol Biol 33, 1-36. 
Dyda, F., Furey, W., Swaminathan, S., Sax, M., Farrenkopf, B. \& Jordan, F. (1993). Catalytic centers in the thiamin diphosphate dependent enzyme pyruvate decarboxylase at 2·4-Angstrom resolution. Biochemistry 32, 6165-6170.

Estramareix, B. \& David, S. (1996). Biosynthesis of thiamine. New J Chem 20, 607-629.

Falco, S. C. \& Dumas, K. S. (1985). Genetic analysis of mutants of Saccharomyces cerevisiae resistant to the herbicide sulfometuron methyl. Genetics 109, 21-35.

Falco, S. C., Dumas, K. S. \& Livak, K. J. (1985). Nucleotide sequence of the yeast ILV2 gene which encodes acetolactate synthase. Nucleic Acids Res 13, 4011-4028.

Geitz, R. D., Schiestl, R. H., Willems, A. R. \& Woods, R. A. (1995). Studies on the transformation of intact yeast cells by the LiAc/SSDNA/PEG procedure. Yeast 11, 355-360.

Gough, J. A. \& Murray, N. E. (1983). Sequence diversity among related genes for recognition of specific targets in DNA molecules. J Mol Biol 166, 1-19.

Hawkins, C. F., Borges, A. \& Perham, R. N. (1989). A common structural motif in thiamin pyrophosphate-binding enzymes. FEBS Lett 255, 77-82.

Hohmann, S. \& Meacock, P. A. (1998). Thiamin metabolism and thiamin diphosphate-dependent enzymes in the yeast Saccharomyces cerevisiae: genetic regulation. Biochim Biophys Acta 1385, 201-219.

Ibdah, M., Barllan, A., Livnah, O., Schloss, J. V., Barak, Z. \& Chipman, D. M. (1996). Homology modeling of the structure of bacterial acetohydroxy acid synthase and examination of the active site by site-directed mutagenesis. Biochemistry 35, 16282-16291.

Iwashima, A., Nishino, H. \& Nose, Y. (1973). Carrier mediated transport of thiamine in baker's yeast. Biochim Biophys Acta 330, 222-234.

Kawasaki, Y., Nosaka, K., Kaneko, Y., Nishimura, H. \& Iwashima, A. (1990). Regulation of thiamine biosynthesis in Saccharomyces cerevisiae. J Bacteriol 172, 6145-6147.

Lindqvist, Y., Schneider, G., Ermler, U. \& Sundstrom, M. (1992). Three-dimensional structure of transketolase, a thiamine diphosphate dependent enzyme, at 2.5 Angstrom resolution. EMBO J 11, 2373-2379.

Mortimer, R. K. \& Hawthorne, D. C. (1966). Genetic mapping in Saccharomyces. Genetics 53, 165-173.

Muller, Y. A. \& Schultz, G. E. (1993). Structure of the thiamine and flavin-dependent enzyme pyruvate oxidase. Science 259, 965-967.

Nilsson, U., Lindqvist, Y., Kluger, R. \& Schneider, G. (1993). Crystal-structure of transketolase in complex with thiamine thiazolone diphosphate, an analog of the reaction intermediate, at 2.3 Angstrom resolution. Febs Lett 326, 145-148.
Nishimura, H., Kawasaki, Y., Kaneko, Y., Nosaka, K. \& Iwashima, A. (1992). A positive regulatory gene, THI3, is required for thiamine metabolism in Saccharomyces cerevisiae. J Bacteriol 174, 4701-4706.

Nosaka, K., Nishimura, H., Kawasaki, Y., Tsujihara, T. \& Iwashima, A. (1994). Isolation and characterization of the THI6 gene encoding a bifunctional thiamin-phosphate pyrophosphorylase/ hydroxyethylthiazole kinase from Saccharomyces cerevisiae. J Biol Chem 269, 30510-30516.

Orr-Weaver, T. \& Szostak, J. (1983). Yeast recombination - the association between double-stranded gap repair and crossingover. Proc Natl Acad Sci US A 80, 4417-4421.

Polaina, J. (1984). Cloning of the ILV2, ILV3 and ILV5 genes of Saccharomyces cerevisiae. Carlsberg Res Commun 49, 577-584.

Praekelt, U. M., Byrne, K. L. \& Meacock, P. A. (1994). Regulation of THI4 (MOL1), a thiamine biosynthetic gene of Saccharomyces cerevisiae. Yeast 10, 481-490.

Rose, M. D., Novic, P., Thomas, J. H., Botstein, D. \& Fink, G. R. (1987). A Saccharomyces cerevisiae genomic plasmid bank based on a centromere containing shuttle vector. Gene 60, 237-243.

Rothstein, R. J. (1983). One-step gene disruption in yeast. Methods Enzymol 101, 202-211.

Ryan, E. D. \& Kohlhaw, G. B. (1974). Subcellular localization of isoleucine-valine biosynthetic enzymes in yeast. J Bacteriol 120, 631-637.

Sambrook, J., Fritsch, E. F. \& Maniatis, T. (1989). Molecular Cloning: a Laboratory Manual, 2nd edn. Cold Spring Harbor, NY : Cold Spring Harbor Laboratory.

Sayle, R. A. \& Milner-White, E. J. (1995). RASMOL: biomolecular graphics for all. Trends Biochem Sci 20, 374-376.

Sherman, F. (1991). Getting started with yeast. Methods Enzymol 194, 3-21.

Suzuoki, J. (1955). Thiamine uptake by yeast cells. J Biochem $\mathbf{4 2}$, 27-39.

Wang, J. J., Martin, P. R. \& Singleton, C. K. (1997). A transketolase defect in a Wernicke-Korsakoff syndrome patient. Alcohol Clin Exp Res 21, 576-580.

Westerfeld, W. W. (1945). A colorimetric determination of blood acetoin. J Biol Chem 161, 495-502.

Wickerham, L. J. (1951). Taxonomy of yeast. US Dep Agric Tech Bull 1029, 11-56.

Yanisch-Perron, C., Vieira, J. \& Messing, J. (1985). Improved M13 phage cloning vectors and host strains - nucleotide sequences of the M13mp18 and pUC19 vectors. Gene 33, 103-119.

Received 30 April 2001; accepted 29 May 2001. 